\section{The role of Thalassemia International Federation in the promotion, of global, regional and national policy of control of hemoglobin disorders: a brief overview}

\section{Dedicated to and in honor of late Professor Renzo Galanello}

\section{Introduction}

Improving global health remains the target of many international, regional and national official health bodies struggling to coordinate limited economic and human resources in order to ensure equal access of all to quality healthcare.

The collective work of the nations focusing on health is mainly coordinated through the United Nations (UN), through its official agency, the World Health Organization (WHO) headquarters, its regional offices and its collaborating centers. In this context, WHO maintains a central role in promoting global health and advancing several health priorities on the national, regional and global level, by directing or coordinating international health projects, promoting health policies and providing technical assistance to different countries.

\section{Universal health coverage and universal access}

Universal health coverage has been set as a possible umbrella goal for health in the WHO post-2015 development agenda.

Universal health coverage is the goal that all people obtain the health services they need without risking financial hardship from unaffordable out-of-pocket payments.

Access has three dimensions:

- Physical accessibility. This is understood as the availability of good health services within reasonable reach of those who need then and of opening hours, appointment systems and other aspects of service organization and delivery that allow people to obtain the services when they need them.

Financial affordability. This is a measure of people's ability to pay for services without financial hardship. It takes into account not only the price of the health services but also indirect and opportunity cost (e.g. the costs of transportation to and from facilities and of taking time away from work).
Affordability is influenced by the wider health financing system and by household income

Acceptability. This captures people's willingness to seek services. Acceptability is low when patients perceive services to be ineffective or when social and cultural factors such as language or the age, sex, ethnicity or religion of the health provider discourage them from seeking services.

The World Bank is another major organization involved heavily in international health and a number 0 other organizations within the UN, focus efforts and work on specific heath agendas. In addition, a number of other nongovernmental organizations (NGOs) invest considerably on health and amongst those which are becoming increasingly important in the sphere of global humanitarian efforts are the International Committee of the Red Cross (ICRC), Médecins Sans Frontières, the International Rotary Club, March and Dimes and Bill Gates Foundation and which stand out indeed for their involvement and success to global health promotion.

Certainly many such organizations exist and contribute immensely to the area of health at the national and regional level and their work contributes significantly to the promotion of health services at the country level.

However, promoting global health and achieving measurable outcomes on a global scale remains a far reaching goal and constitutes a complicated agenda in a world of continued storms caused by wars, famine, natural disasters, and mass population displacements. Apart from the above international organizations, during the past few decades, the work of global health initiatives and international projects has become increasingly important, since they contribute a considerable portion of funds devoted to global health. The work of such initiatives requires enormous support from grass root organizations across the world in order to offer meaningful results at the population level. A successful paradigm of an international non-governmental grass root patient-oriented organization focusing initially, in the early days, specifically on thalassemia and in more recent years on other hemoglobin disorders and rare anemias, is the Thalassemia International Federation (TIF).

Thalassemia syndromes, together with other disorders of the hemoglobin molecule, mainly sickle cell disease (SCD), collectively referred to as hemoglobinopathies ( $\mathrm{Hb})$, are the commonest single gene disorders among all clinically important hereditary disorders around the world. Thalassemias, the most important of which are the $\alpha$ - and $\beta$-thalassemias and SCD, have received particular attention in the past decades and continue to attract strong interest from clinicians, public health professionals and policy makers due to their significant clinical and enormous social and economic repercussions.

The objective of this current paper which is dedicated to and prepared in honor of late Professor Renzo Galanello, is to present a comprehensive overview of the mission, goals and objectives of TIF, initially founded to address $\beta$ thalassemia but in more recent years expanded in scope and activities to provide support to other thalassemia syndromes, SCD and other rare anemias.

\section{Establishment of the Thalassemia International Federation}

Cyprus, Italy and Greece, the Mediterranean Sea countries of South Europe, were amongst the first countries of the world, in the 1960s to recognize thalassemia initially and on the way SCD, as major public health challenges, subsequently placing them as priorities on their national health agendas. WHO, public health officials, policy makers, in many instances the Church leaders, the extended medical community, the patients and their families, and the communities at large, joined hands during the years 1960-1980 in a struggle of its strength and extent to better understand the natural history of these diseases and develop and implement programs to effectively prevent, or minimize, the annual affected births while at the same time divert resources and build up programs for effectively monitoring and managing these disorders.

Through the years 1960-1985 the research outcomes, the conclusions from clinical studies and observations undertaken by motivated scientists and medical experts, mainly pediatricians, including Professors Antonio Cao, Renzo Galanello, Bernadette Modell, Sir David Weatherall, Phaedon Fessas, Calogero Vullo, Victor Hoffbrand, Prewase Wasi, Dimitris Loukopoulos, Christos Kattamis, and others, led to the accumulation of knowledge and experiences embarking health authorities at the national level to build effective control programs including the two major components: prevention and management. Many are the health professionals who showed true and in depth commitment to the promotion of such programs and the list above is by no means exhaustive, asking for an understanding and forgiveness for any commissions that may indeed be very important.

These researchers supported the work of WHO in this filed and indeed constituted the first WHO working group on hemoglobinopathies, established in 1981, which developed the first control guidelines with the available poor knowledge existing at the time. 
By the mid 1980s and following the success achieved more on the prevention side rather than on the treatment end, of the control strategies in Southern European Mediterranean countries, the very few patients/parents support groups existing in these countries at the time, decided to join hands with the medical experts and the WHO with the objective to stimulate interest and motivation amongst the medical/research community for further improvements in the area of management. It was this time (1985) that TIF was born, the patients and parents having realized by then, that the problem was not geographically confined to the region around the Mediterranean, as previously believed, nor to some Western countries like France, UK and USA which traditionally hosted immigrant population (from countries where $\mathrm{Hb}$ disorders were prevalent). The WHO reports at the time, demonstrated that these disorders followed a pattern of epidemiology related to malaria endemic or previously endemic areas of the world. As a consequence these disorders were anticipated to occur widely across the world particularly in low resource countries.

Today of course, their occurrence expanded to cover almost every country across the world these diseases literally introduced into the indigenous population, as a result of heavy population movements and immigration of population seeking work and a better life outside their home countries.

In 1986, TIF was established and in 1987 the organization was registered as a humanitarian, NGO under the Cyprus registry legal framework.

The Federation's constitution ensured the patients' oriented nature of its existence and activities and defined its mission for safeguarding the rights of all patients for quality health care.

\section{Mission, goals and objectives of the Thalassemia International Federation}

The vision of this Federation, being the establishment of equal access to all patients for quality health care, defines its mission: the development and establishment of national control programs in every country where $\mathrm{Hb}$ disorders exist as the only way to ensuring effectiveness and sustainability of appropriate health care services. To realize its mission and materialize its mission TIF focuses on: i) establishing a line of effective and productive collaboration with the expert medical/scientific communities and on; ii) becoming officially and actively involved with WHO, its regional offices and collaborating offices and other official health related bodies at the national, regional and international level.

\section{Thalassemia International Federation: activities, milestones and highlighted achievements}

Six types of activities define and describe the work of TIF to date.

\section{Establishment/promotion}

of national thalassemia/

sickle cell disease associations

Today patients/ parents from 118 national organizations from 58 countries are members of TIF.

\section{Educational programs}

The program is comprised of four major pillars: The organization of events, conferences, seminars, workshops at the national, regional and international level: i) national (58); ii) regional (24); iii) international (23); iv) 22,000 health professionals/ patients/parents from 64 countries.

- The preparation, publication, translation and distribution of publications to the medical and patients/parents communities at the public at large (Table 1).

- e-MSC course in Hematology (2006-2013): 75 medical specialists qualified to date. This unique course offers health professionals from around the world the opportunity to pursue a specialist qualification from a leading University with minimum disruption to professional and personal lives.

- Training/fellowship/research grants.

\section{Sultan Bin Khalifa International Thalassaemia Award}

A new award program for significant contributions in the field of thalassemia and other Hemoglobinopathies has been established by H.H. Dr. Sheikh Sultan Bin Khalifa Al Nahyan, through His Highness Humanitarian \& Scientific Development Foundation in partnership with TIF (SITA Award: http://www.thalassaemia.org.cy/collaboration-partnerships-networks/sultan-bin-khalifa-award.shtml).

We are proud to take the lead in establishing such a prestigious award in an endeavor to strengthen efforts to educate the patients and the public about these genetic disorders, as well as to provide further motivation and encouragement to all those working in research and medical/clinical field to improve the health and the quality of life of patients with thalassemia.

The awards aim is to bring thalassemia and other hemoglobinopathies to the forefront of the political and health agendas globally. The awards will be given every two years and include both national and international cate- gories with monetary and non-monetary prizes. Winning individuals and/or organizations will be announced during the biennial international conferences organized by TIF, followed by an award ceremony in Abu Dhabi.

The INTERNATIONAL AWARD CATERGORIES include:

- Grand International Award for life-long scientific contribution in the field of Thalassemia/Hemoglobinopathies.

International Award for Innovative Medical Research.

- International Award for Clinical Center for Excellence.

International Award for Thalassemia Society of Excellence.

- International Scholarship for Translational Research in Thalassemia.

- International Leadership in Thalassemia Award.

Professor Renzo Galanello Fellowship - a newly established training course in memory of the later distinguished scientist. It offers 4-6 months clinical training of medical specialists in a recognized Reference Centre.

\section{Collaborations/partnerships/ networks}

TIF has established collaborations with 350 medical specialists in 62 countries.

TIF has developed four networks of health professionals: i) endocrine; ii) cardiology; iii) hepatology; iv) nursing.

TIF has engaged in relations with official bodies: i) World Health Organization (WHO) in official relations since 1996; ii) EU/European Parliament/European Commission/European Medicines Agency (EMA); iii) Association of Southeast Asian Nations (ASEAN); iv) European Public Health Alliance (EPHA).

Patients oriented organizations: i) International Alliance of Patients' Organizations (IAPO); ii) European Organization for Rare Diseases (EURORDIS); iii) European Platform for Patients' Organizations, Science and Industry (EPPOSI); iv) European Patients' Forum (EPF).

\section{Projects}

TIF has undertaken, and is involved as a partner, leader or coordinator in many projects at all levels focused on promoting health and quality of life and in more recent years on strengthening reference centers, networks and e-based programs including e-learning, epatients registries, expert patients applications, telemedicine, etc.

\section{Policy development}

Needless to underscore the significant 
effort and work TIF focuses on the involvement and active engagement in new policies promotion and in existing policies, reforming and amending.

\section{Communication}

Transparent and timely communication and objectives, mission, results of TIF's work and outcomes of its activities constitute a major part of the TIF offices everyday commitment and this is achieved mainly through: i) e-communication; ii) TIF Magazines (62 issues to date - three monthly to 3500 readers); iii) enewsletters (started in 2012); iv) Facebook (started in 2013); v) Twitter (coming soon); vi) and TIF website (reviewed, updated and upgraded regularly). To promote successfully its activities, TIF has created medical/scientific advisory groups from all disciplines and currently working with 20 international experts, 50 regional and more than 200 national experts in more than 60 countries.

\section{Impact of the Thalassemia International Federation}

The work of TIF has had a significant impact in the: i) strengthening of the patients' voice and involvement globally; ii) the prioritization of $\mathrm{Hb}$ disorders on international (WHO), regional and national official health agendas; iii) promotion of education/motivation of medical/scientific communities; iv) promotion of education of the patients/parents community; and v) spread of awareness and sensitization of the community at large at the country level.

Amongst the above-described activities, TIF's educational program stands out for its impact and contribution to the education and building up of the knowledge of all involved communities and stakeholders, and the contribution of TIF's medical/scientific advisory groups in its success has been truly exemplary.

Renzo Galanello, Ali Taher, John Porter, Antonio Piga, Vincenzo De Sanctis, Nica Cappellini, Aurelio Maggio, Beatrice Wonke, Paul Telfer, Vip Viprakasit, Malcolm Walker, Athanasios Aesopos, Dudley Pennel, Constantina Politi, Ersi Voskaridou, Faroukh Shah, are amongst TIF's main valued collaborators and partners to the development and success of its educational program.

Their research and clinical work and studies have been invaluable to the better understanding of the pathophysiology of thalassemia syndromes including the non transfusion dependent thalassemias and SCD and have resulted in the development of more effective tools for monitoring, prevent development of complications and managing more appropriately and effectively these disorders.

Historically, through their close collaboration with TIF, its was possible to put together the first comprehensive guidelines on Prevention of thalassemia's \& other hemoglobinopathies, Vol. I-II, the Guidelines for the clinical management of thalassemia (2007, 2008, 2013), the Guidelines for the management of non transfusion dependent thalassemia
(NTDT) (2013), the Emergency management of thalassemia (2012), the Guide for the hemoglobinopathy nurse (2013). All of them together and each one separately have contributed to the great impact that the work of TIF has had on the promotion of knowledge and education of medical community.

These compose indeed a complete set of books constituting to date the richest and perhaps the only reference material focused on guiding medical specialists on how to effectively prevent and treat these disorders, and policy makers on how to better tailor the planning of services and the prioritization of these disorders on national health agendas. Without any doubt these publications coupled with the conferences and workshops have been amongst the greatest successful activities of this Federation.

\section{Resolutions}

The work of TIF has in addition greatly contributed and supported WHO in its adoption of two specific Resolutions by World Health Assembly (WHA) and the ex Board:

- WHA59.20 - Sickle Cell Anemia

- EB118.R1 - Thalassemia and other Hemoglobinopathies

- WHA 63.12 - Availability of blood

- WHA 63.17 - Births Defects

- WHA 63.18 - Viral Hepatitis

At the European level, TIF's work has significantly contributed to the undertaking and recommendations of the EU (through specific projects: ENERCA, ITHANET) on the develop-

Table 1. Thalassemia International Federation: educational programs.

\begin{tabular}{|c|c|c|c|}
\hline Publication & Year & Languages & Copies/distribution \\
\hline Blood safety kit manual for patients and parents & 1999 & 1 & $6000 / 25$ countries \\
\hline Guidelines for the clinical management of thalassemia $-1^{\text {st }}$ edition & 2000 & 10 & $50,000 / 60$ countries \\
\hline Compliance to iron chelation therapy with desferrioxamine & 2001 & 12 & $40,000 / 45$ countries \\
\hline About thalassemia & $2003 ; 2007$ & 23 & $32,000 / 45$ countries \\
\hline Prevention of thalassemias and other hemoglobinopathies - Vol. I & $2003 ; 2013$ & $\begin{array}{l}2 \\
1\end{array}$ & $\begin{array}{c}\text { 5000/32 countries } \\
\text { 2000/ongoing }\end{array}$ \\
\hline Prevention of thalassemias and other hemoglobinopathies - Vol. II & $2005 ; 2012$ & $\begin{array}{l}1 \\
1\end{array}$ & $\begin{array}{l}\text { 5000/32 countries } \\
1000 / \text { ongoing }\end{array}$ \\
\hline Guidelines for the clinical management of thalassemia $-2^{\text {nd }}$ edition $\& 2^{\text {nd }}$ revised edition & $2007 ; 2008$ & 8 & $12,000 / 30$ countries \\
\hline Patients' Rights & 2007 & 6 & $10,000 / 25$ countries \\
\hline A guide to establishing a non-profit patient support group & 2007 & 6 & $7000 / 20$ countries \\
\hline $\begin{array}{l}\text { Set of educational booklets: } \\
\text { 1. } \beta \text {-thalassemia } \\
\text { 2. } \alpha \text {-thalassemia } \\
\text { 3. Sickle cell disease }\end{array}$ & $2007 ; 2013$ & 10 & 5000/ongoing (Cyprus; Greece) \\
\hline Sickle cell disease - Booklet for patients, parents and the community & 2008 & 3 & $5000 / 15$ countries \\
\hline All about thalassemia - Cartoon booklet & 2010 & 2 & $10,000 / 15$ countries \\
\hline Guidelines for the management of non-transfusion dependent thalassemia (NTDT) & 2013 & 1 & 5000/ongoing \\
\hline A guide for the hemoglobinopathy nurse & 2012 & 1 & 1000/ongoing \\
\hline Emergency management of thalassemia & 2012 & 1 & 1000/ongoing \\
\hline
\end{tabular}


ment of criteria for Reference Centers and networks for rare anemias but also on promoting research and recommendations for their control in every EU country.

\section{Conclusions}

In conclusion and in memory of our close and long-term collaborator Professor Renzo Galanello, I would like to reiterate the commitment of TIF to continue and even strengthen its activities around the world for increasing access of every patient in every country of the world to quality health care and for motivating policy makers to develop national, effective sustainable programs for prevention.

Professor Galanello is remembered as one of the biggest contributors to the better understanding of the pathophysiology, treatment and prevention of these diseases and he will always be cherished by TIF as a great scientist, as an outstanding collaborator and by the global patient community as a unique personality of a competent doctor, a devoted scientist and researcher and a kind, caring treating physician. Combination indeed very rarely found in a single individual. TIF dedicates this brief history report of TIF's history and activities to Professor Renzo Galanello as an expression of immense gratitude and most sincere appreciation for his vast, invaluable contribution to TIF's global work and impact.

Androulla Eleftheriou Executive Director, Thalassemia International Federation E-mail: thalassaemia@cytanet.com.cy 